\title{
Retraction Note: Evaluation and research of comprehensive seismic observation technology based on optical fiber sensing
}

\author{
Hongwei Yang ${ }^{1} \cdot$ Jin Peng ${ }^{1} \cdot$ Xu Sun ${ }^{1} \cdot$ Gang Chen ${ }^{1}$
}

Published online: 9 December 2021

(c) Saudi Society for Geosciences 2021

Retraction Note: Arabian Journal of Geosciences (2021) 14: 1803 https://doi.org/10.1007/s12517-021-08,163-3

The Editor-in-Chief and the Publisher have retracted this article because the content of this article is nonsensical. The peer review process was not carried out in accordance with the Publisher's peer review policy. Authors Hongwei Yang, Jin Peng and Gang Chen have not responded to correspondence regarding this retraction. The Publisher has not been able to obtain a current email address for author Xu Sun.

The original article can be found online at https://doi.org/10.1007/ s12517-021-08163-3.

Hongwei Yang

13890869692@163.com

1 School of Information, Southwest Petroleum University, Nanchong 637000, Sichuan, China 